\title{
Fractographic Analysis of Tensile Failures of Aerospace Grade Composites
}

\author{
Masa Suresh Kumar ${ }^{\text {**, Kesarabandi Raghavendra }}{ }^{\text {a }}$ Magalapalaya Anjanappa Venkataswamy ${ }^{\text {a }}$ \\ Honnudike Venkateshwararao Ramachandra ${ }^{\mathrm{b}}$ \\ ${ }^{a}$ Electron Microscopy group, Materials Science Division, National Aerospace Laboratories, \\ Council of Scientific an Industrial Research - CSIR, Bangalore 560017, India \\ ${ }^{\mathrm{b}}$ Advanced Composites Division, National Aerospace Laboratories, \\ Council of Scientific and Industrial Research - CSIR, Bangalore 560017, India
}

Received: October 18, 2011; Revised: July 17, 2012

\begin{abstract}
This paper describes fractographic features observed in aerospace composites failed under tensile loads. Unidirectional Carbon Fibre Reinforced Plastic (UD CFRP) and Unidirectional Glass Fibre Reinforced Plastic (UD GFRP) composite specimens were fabricated and tested in tension. The morphology of fractured surfaces was studied at various locations to identify failure mechanism and characteristic fractographic features. CFRP composites displayed transverse crack propagation and the fracture surface showed three distinct regions, viz., crack origin, propagation and final failure. Significant variations in the fractographic features were noticed in crack propagation and final failure regions. Crack propagation region exhibited brittle fracture with chevron lines emanating from the crack origin. The entire crack propagation region exhibited radial marks on the individual fibre broken ends. On the other hand, the final fracture region revealed longitudinal matrix splitting and radial marks in majority of locations, and chop marks at some locations. The change in fracture mode in the final fracture was attributed to superimposition of bending loads. GFRP composites exhibited broom like fracture with extensive longitudinal splitting with radial marks present on individual fibre broken ends. Transverse fracture was observed at a few locations. These fracture features were analyzed and correlated with the loading conditions.
\end{abstract}

Keywords: composite(s), fractography, failure modes

\section{Introduction}

Composite materials have become an alternative to metallic materials because of their unique properties like high specific stiffness, specific strength and tailorable properties. During the past couple of decades, there has been growing interest in use of carbon and glass fibre reinforced composite materials for the fabrication of aerospace structures. In early years, the composite materials were mainly used in secondary structures such as fairings, small doors and control surfaces in aircraft vehicles. But, with the advent of newer and newer technologies, the composite materials have found applications in primary structures such as wings and fuselages. It is estimated that the use of composites in commercial transport aircraft would be about $50 \%$, whereas the same in the military aircraft could be as high as $80 \%$ by weight 1 . With increased use of these materials, failures are inevitable. Failures in composite structures can occur during various stages in the manufacturing process development, during simulation tests or during service. There is a need to conduct failure analysis to identify the cause of failure in an effort to provide useful feedback to designer, manufacturer and user. The first step for failure analysis is identification of the failure mode. This can be established through fractographic study. When material fails, it leaves signatures on its fracture

*e-mail: mskumar@nal.res.in surface typical of that failure. The signatures provide vital information which facilitates identification of the location and source of failure, probable causes of failure etc., and also, in formulation of the sequence of previous events. It also provides valuable information about the local service environment and state of stress at the time of crack initiation, propagation and final failure.

The fracture modes in composites are complex and are influenced by several factors such as, number of plies in the structure, stacking sequence, direction of loading, application environment etc. The major failure modes in composites can be either matrix or fibre dominated ${ }^{2}$. Interlaminar and intralaminar fractures are matrix dominated whereas translaminar fractures are fibre dominated ${ }^{3}$. The damage initiation and propagation in composites occur through various failure modes including matrix cracking, delamination, fibre breakage, interfacial debonding, fibre buckling, kinking etc. In several applications, the aerospace components are subjected to tensile loading conditions. The tensile failures are caused due to overload or stress concentrations acting as failure initiation sites. The fracture in unidirectional fibre reinforced composites subjected to tensile loads may be brittle, brittle with fibre pullout or random4. The fracture features mostly depend on the interfacial bond characteristics. Composites displaying good interfacial bonding characteristics exhibit brittle fracture 
while those with poor interfacial bonding show brittle fracture with fibre pull out. Moderately bonded ones, on the other hand, exhibit random fracture.

The failure mechanisms in unidirectional composites under tensile loads have been examined by several authors. Zweben and $\operatorname{Rosen}^{5-6}$ predicted that tensile failures in UD CFRP are due to statistical accumulation of fibre damage with fracture at single cross section of the specimen. The model also considers that the broken fibres are not necessarily to be adjacent and the failure is likely to occur due to stress concentration. The linear elastic fracture mechanics model ${ }^{4}$ considers CFRP material as an anisotropic, homogeneous material and the tension failure due to the development of a single flaw of critical size, followed by crack propagation through successive adjacent regions of fibres and matrix. Fuwa et al. ${ }^{7}$ showed experimentally that CFRP is weakened by a number of internal failures that are not necessarily connected. They conclude that the basic mechanisms of failure are statistically determined and are not a result of straightforward crack propagation. Jacob failure model $^{8}$ predicts that failure in UD GFRP does not occur at a single cross section. Rather, bundles of fibres fracture at different locations along the specimen followed by matrix splitting or debonding running parallel to the fibres. Cook and Gordon ${ }^{9}$ considered tensile failures in composites via matrix splitting followed by fibre fracture. Clearly, there are some inconsistencies in these proposed mechanisms of failures in composite materials. It is important to note that the high stresses near free edges can easily trigger failure in a laminate ${ }^{10}$. Fractographic analysis of polymer composite materials has been subject of considerable interest in the recent years. Several investigators ${ }^{11-23}$ have studied the fractographic features of various fibre reinforced composites and identified characteristic features under various loading conditions including environmental effects like temperature and moisture.

The objective of the present study is to identify the tensile failure mechanism and characteristic fracture features in present generation aerospace grade UD CFRP and GFRP composites through fractographic analysis. Earlier studies ${ }^{11}$ were focused on identification of characteristic features typical of tensile loads. The present study examines fractographic features at various locations, viz., crack initiation, propagation and final failure regions. The variations in the fractographic features in crack propagation and final failure regions have been highlighted.

\section{Experimental Procedure}

In the present study, $2 \mathrm{~mm}$ thick UD CFRP laminates prepared from carbon epoxy prepeg sheet cured at $120^{\circ} \mathrm{C}$ in autoclave for 1 hour under pressure of 7 bar followed by post curing at $170{ }^{\circ} \mathrm{C}$ for 4 hours, were used. The carbon fibres were Hexcel AS4 type and the matrix was modified 914 grade epoxy. On the other hand, UD GFRP composite specimens with a thickness of $2 \mathrm{~mm}$ were fabricated by wet lay-up technique. The UD E-glass fabric and room temperature curable (LY 556, HY 951) epoxy resin systems were used to prepare the composite laminates. The volume fraction of fibres in CFRP, GFRP was measured by chemical dissolution and burning methods respectively and found to be $55 \%$ for CFRP and $45 \%$ for GFRP. CFRP/GFRP test specimens measuring $12.5 \mathrm{~mm}$ wide were cut from the laminates using a diamond cutter.

The test specimens were end-tabbed using CFRP composites (about $2 \mathrm{~mm}$ in thickness) to prevent damage to the specimen during testing. The test specimens were prepared as per ASTM D3039 standard with a gauge length of $140 \mathrm{~mm}$. Tensile testing was conducted using a $10 \mathrm{kN}$ capacity universal testing machine (Instron make) at a constant crosshead speed of $0.05 \mathrm{~mm} / \mathrm{min}$. All tests were carried out under ambient conditions. Minimum of five samples were tested. The fractured samples were examined visually and with the aid of a stereo-binocular microscope. The fracture surfaces were further examined in detail under LEO 440i Scanning Electron Microscope (SEM). The fracture surfaces were vacuum sputter coated with gold before SEM examination.

\section{Results and Discussion}

\subsection{Tensile failure of CFRP}

\subsubsection{Macrofractography}

Figure 1 shows the UD CFRP composite test specimens that failed under tension. It was observed that the fracture surface (Figure 2) was rough in appearance. Moreover, the fracture was non-uniform with three distinct regions on the fracture surface, viz., crack initiation, propagation and final fracture zones. Close examination revealed chevron lines emanating from the failure origin at one of the corners. The presence of chevron lines is helpful in identifying the failure origin and the crack propagation directions. The crack initiation and propagation regions were found to occupy over an area encompassing 50-60\% of the total width of the sample. A few longitudinal splits were noticed in the crack propagation region on either side of the fracture. These splits were found not extending to the mating part. Fractures on either side of the split appeared to be continuous, uniform and they existed in the same plane. Therefore, these splits are considered to have occurred after primary fracture. The macrofractographic features in the final fracture region (Figure 3) were found to be different

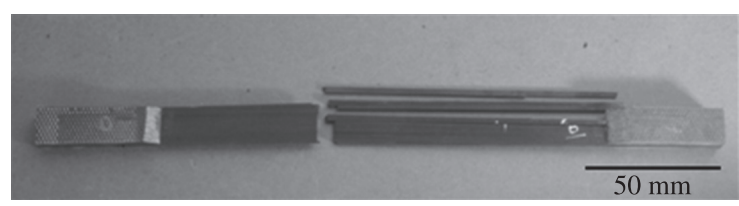

Figure 1. Photograph of CFRP test sample failed under tensile load.

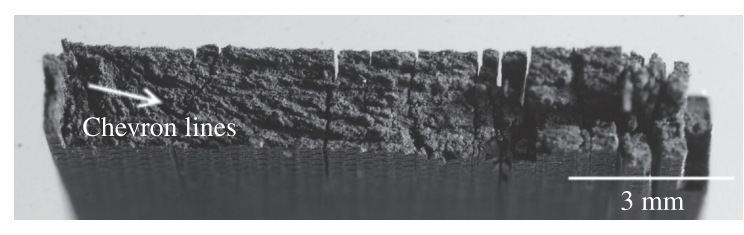

Figure 2. Macrofractograph of a specimen that failed under tensile load. 


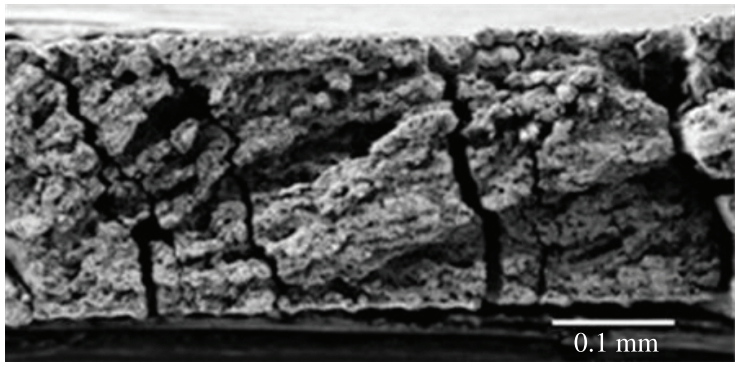

(a)

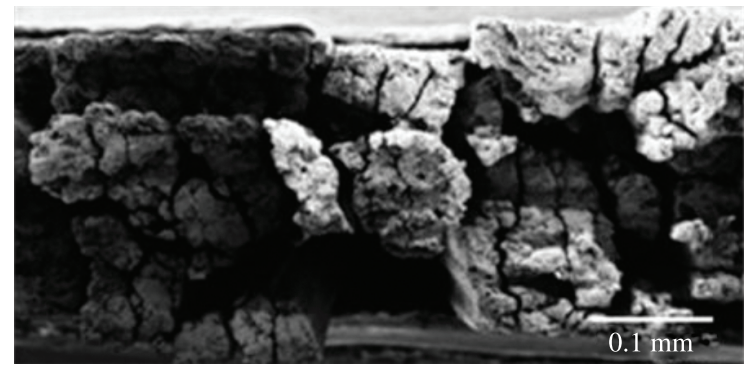

(b)

Figure 3. Longitudinal splitting in (a) crack propagation region, and (b) final fracture region.

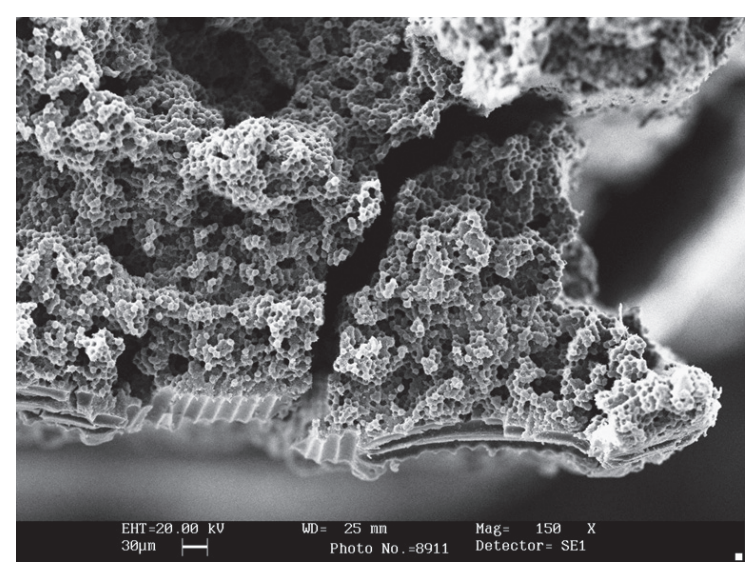

Figure 4. Close-up view of the crack initiation region.

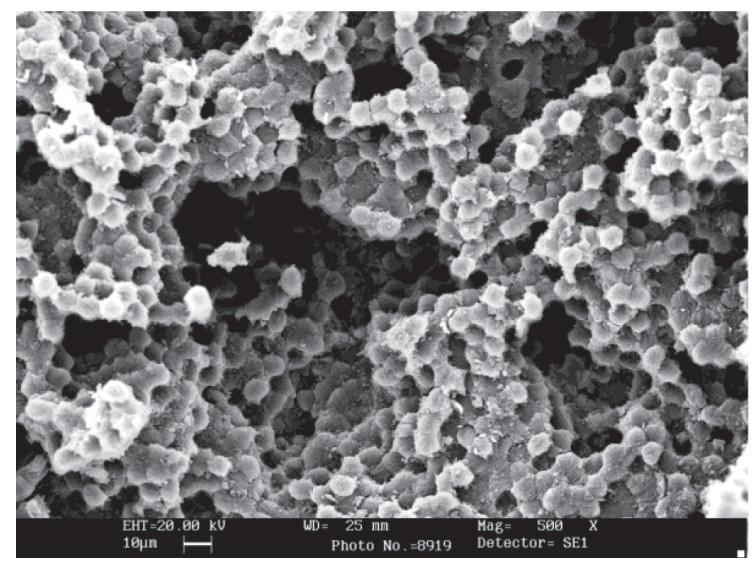

(a) from the crack propagation region. The final fracture region displayed a step fracture at different plane with extensive longitudinal splits. In this case, the step fracture was not related to bridging failure where in interaction of two cracks initiated in different zones during longitudinal fracture of the matrix, rather it was created due to successive fracture. It is important to note that longitudinal splits observed in the final fracture region has an extension to its mating part and hence, it appears to be a primary fracture event. The macrofractographic features that are present on final fracture region are also helpful in identifying the failure origin.

\subsubsection{Microfractography}

The crack initiation, propagation and final fracture regions were examined in detail under SEM. At crack origin, a set of fibre bundles was found to be broken (Figure 4). This acted as stress concentrator for initiation and propagation of crack under tensile load. The entire fracture surface revealed fibre pull out (Figure 5a). However, the pullout lengths were found to be minimal and hence, they exhibited more or less uniform fracture. At higher magnifications, microscopic radial marks were observed on the fractured fibre surfaces. These radial marks are a typical characteristic feature of tensile failure of composite (Figure 5b). The crack origin and propagation direction identified in the macroscopic study were further confirmed by examining the radials direction on the individual fractured fibres. The local crack propagation direction (Figure 6) was resolved by examining the direction of individual fibre fracture ends. Directly Attributable Fibre Failures (DAFF) concept ${ }^{11}$ was used for identification of local crack propagation direction. The resultant of local crack propagation directions at several regions on the fracture surface were correlated to find out the overall crack propagation direction (Figure 7). The crack propagation direction identified in this manner was found to match well with the direction of chevron lines that were present on the overall fracture surface. Longitudinal split surface revealed hackles ${ }^{24}$. In this case, the hackles were not well delineated because of the toughened nature of the matrix. Figure 8a shows hackles bending towards left. This

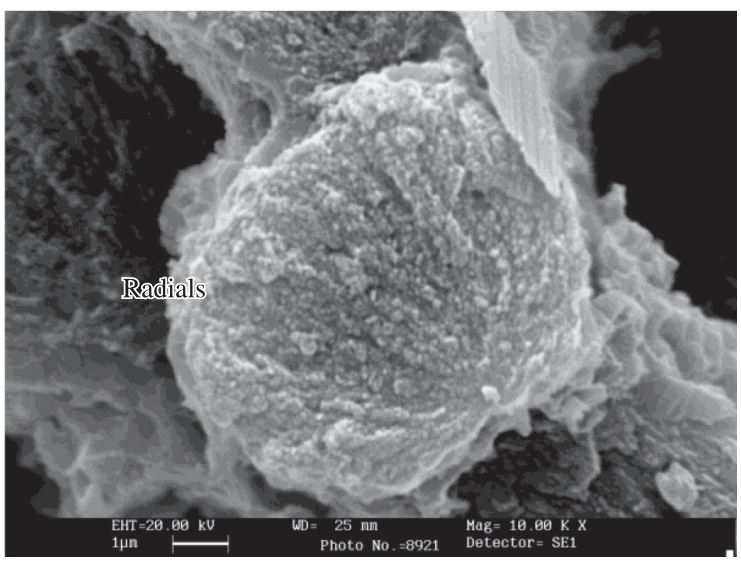

(b)

Figure 5. Microfractographic features showing (a) fibre pull out, and (b) fibre radials. 
indicates that the mating surfaces sheared in a direction shown by half arrow. However, it is interesting to note that the orientation of hackles is in opposite direction on a similar surface of the mating transverse fracture (Figure $8 \mathrm{~b}$ ). This indicates that the transverse fracture occurred prior

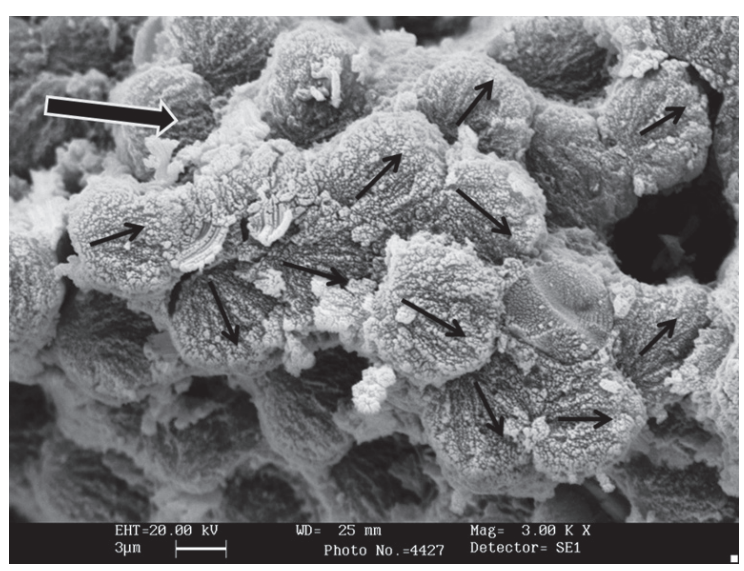

Figure 6. Identification of local crack propagation direction; small arrows indicate individual fibre fracture directions and big arrow represents crack propagation direction in a localized zone. to the longitudinal splits, and it corroborates with the macrofractographic observations. The microfractographic features in the final facture region were different from those in the crack propagation region. This is consistent with the macrofractographic observation. The other common fractographic features such as buckled fibres, crushed fibres, resin fragments were also observed (Figures 9a, b). The final fracture region depicted radials in random direction (Figure 10) which was found to be not in agreement with the general crack propagation direction. At higher magnifications, the chop marks at some locations were indicative of buckling failure (Figure 11). Examination of longitudinal split surfaces in the final failure region revealed hackles. However, the orientation of hackles was found to be identical on a similar longitudinal surfaces of two fractured pieces (Figure 12). This indicates that longitudinal splits occurred prior to transverse fracture and the splits were related to the primary fracture.

\subsubsection{Failure mechanism}

Fractographic study showed that failure originated in the weakest free edge. The free edge acted as a stress concentrator for transverse propagation of crack. The
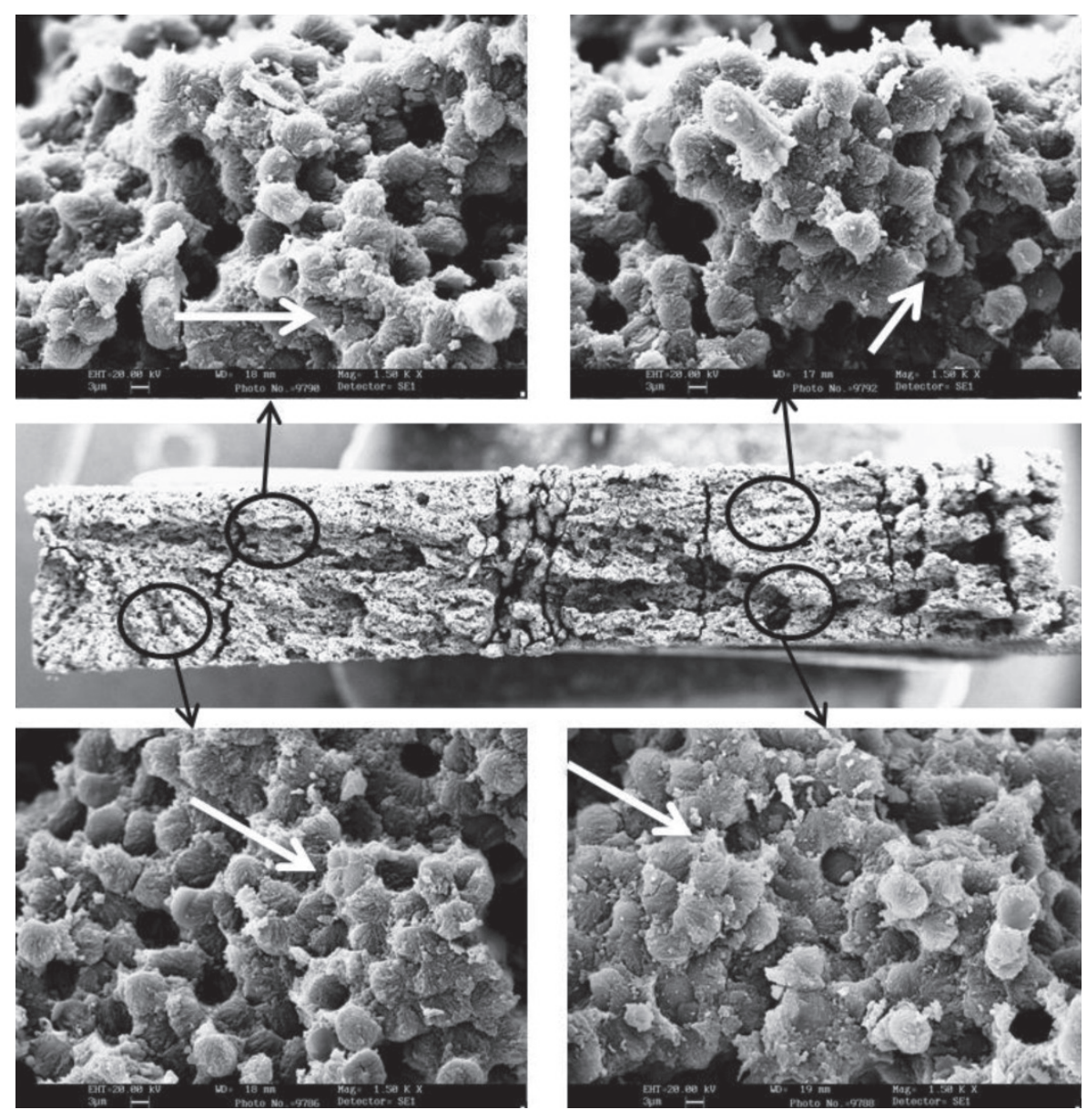

Figure 7. Map of overall crack propagation direction; white arrows indicate local crack propagation direction; dotted arrow indicate the over all crack propagation direction. 


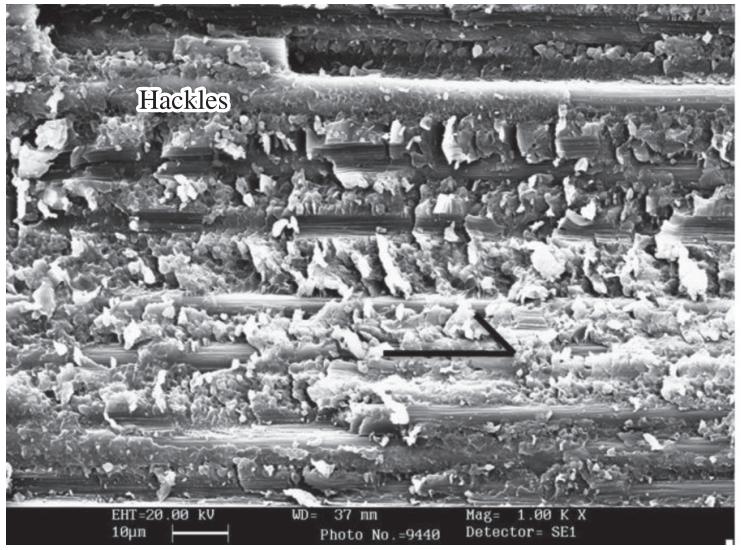

(a)

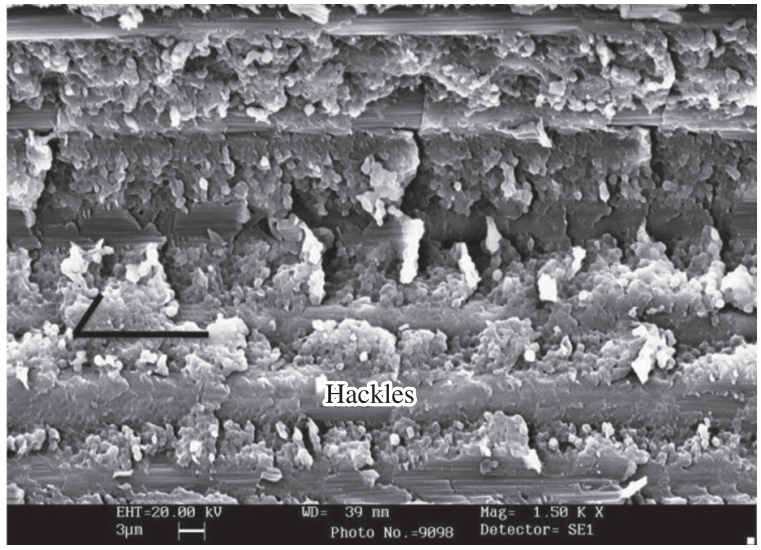

(b)

Figure 8. Hackles observed in the longitudinal split surface at crack propagation region; half-arrow shows the shear direction.

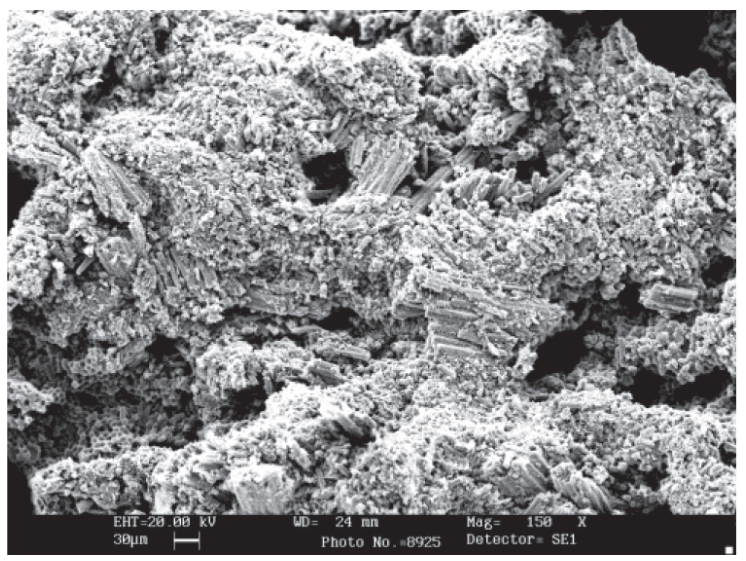

(a)

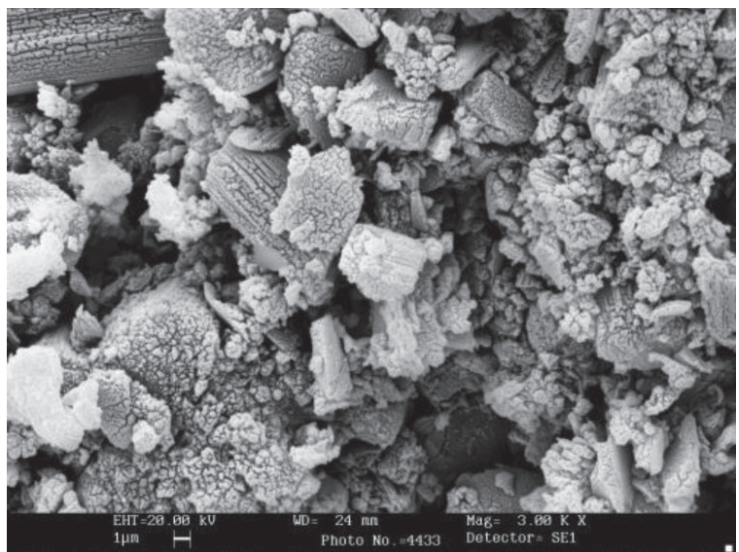

(b)

Figure 9. Microfractographic features in final fracture region showing (a) crushed fibres, and (b) fibre and matrix debris.

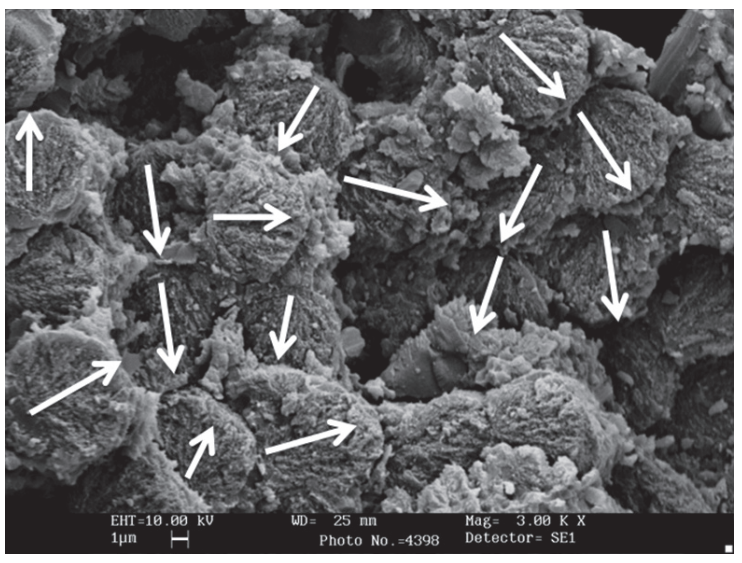

Figure 10. Random fibre fracture directions indicated by white arrows.

broken fibre bundle at free edge was responsible for the crack initiation. After initiation, the crack tends to grow and exhibits a fairly uniform fracture surface. The aerospace grade composite has good interfacial bonding between matrix and fibre, and hence, the crack tends to grow into the matrix with subsequent loading. With continuous increase in load, crack propagation occurred through successive adjacent regions of fibres and matrix. The longitudinal splits observed in the propagation zone were secondary fractures and they were developed after transverse crack propagation. This is established through study of hackle directions (directions are reversed) on similar split surfaces on either side of transverse fracture. After the crack propagated to certain distance, the net load carrying capacity of the composite reduced to that of the applied load resulting in an unstable fracture. The step in final fracture was a successive fracture and it was not related to bridging. The direction of hackles on a similar longitudinal split surface on mating fracture surface shows similar orientation. Therefore, longitudinal splitting is a primary fracture and it occurred before transverse fracture. Longitudinal fracture occurs when the shear stress, $\tau \mathrm{m}$, in the matrix reaches the ultimate shear stress, $\tau \mathrm{mu}$. Longitudinal splitting may occur either due to longitudinal fracture of matrix or debonding process. Since the aerospace grade composite has good interfacial strength, the debonding stress $\tau \mathrm{d}$ is greater than the ultimate shear stress of the matrix, $\tau \mathrm{mu}$, Hence, in such composites, longitudinal fracture of matrix occurs in preference to 
debonding. This is evident from the SEM image where hardly any bare fibres are visible. The final fractured area exhibited buckled fibres and chop marks at few locations. Chops marks represent bending of fibres. It is unusual to observe these features during tensile failure of composite. The presence of chop marks can be explained through the study of state of stress.

The state of stress in the final fracture is shown schematically in Figure 13. As the crack propagates, load (P) path deviates from the line with center of gravity of the specimen resulting in eccentricity (e). The eccentricity produces bending moment $(\mathrm{M})$. The maximum deflection at mid point in such a stuation can be calculated as per the procedure given in Khoshbakht et al. ${ }^{25}$. It appears that the bending loads combined with the tensile overload resulted in extensive longitudinal splitting, fibre bending and step fracture.

\subsection{Tension failure of GFRP}

\subsubsection{Macro and microfractography}

In GFRP composites, fibre bundles got separated from the matrix along their length like in a broom. There was extensive longitudinal splitting. The longitudinal

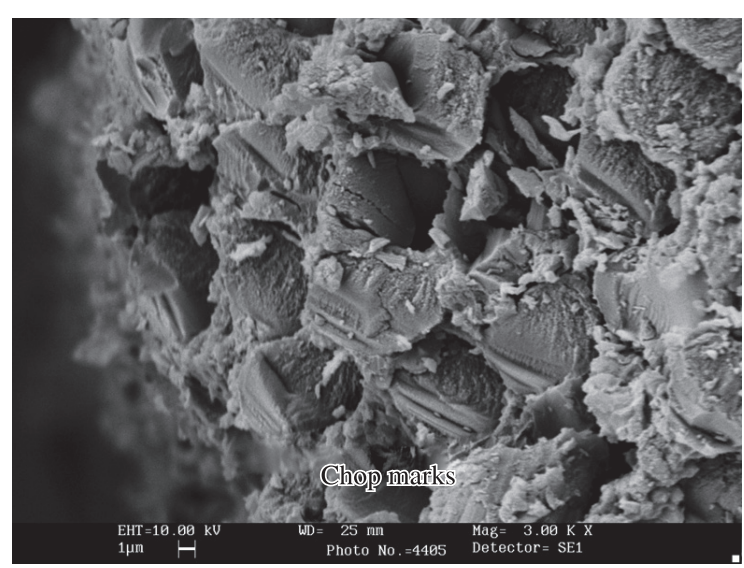

Figure 11. Chop marks indicative of buckling failure.

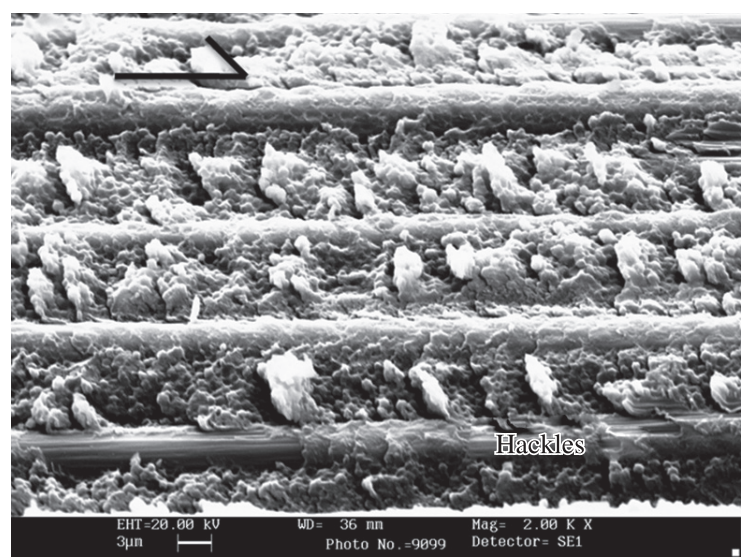

Figure 12. Hackles observed in the longitudinal split surface at final fracture region; half-arrow shows the shearing direction. splitting observed could be a primary or a secondary event. However, in the present case, longitudinal splitting was a primary event. The mechanism by which longitudinal splitting occurs due to debonding is induced in fibre reinforced composites was first identified by Cook and Gordon ${ }^{9}$. When the crack initiates and propagates through the matrix in unidirectional laminates, the tensile stress ahead of the crack $\sigma \mathrm{c}$, is associated with shear $\tau \mathrm{m}$ and the ultimate shear stress near the fibre $\tau \mathrm{mu}$. The fibre matrix interface strength is weak in GFRP composites, and the debonding stress $\tau d$ is less than the ultimate shear stress of the matrix, $\tau \mathrm{mu}$, Hence, longitudinal splitting due to debonding is favoured. This leads to broom-like failure (Figure 14). The longitudinal splitting due to debonding produces large difference in heights between the ends of the individual fractured fibres. Secondary transverse fractures of individual fibres occur in certain regions. Examination of fibre fracture ends revealed that the tensile fracture features like pull outs (Figure 15a) radials (Figure 15b) were oriented in random direction in each fibres. Since the tensile fracture was like broom, it was not possible to identify the crack propagation direction on the fracture surface.

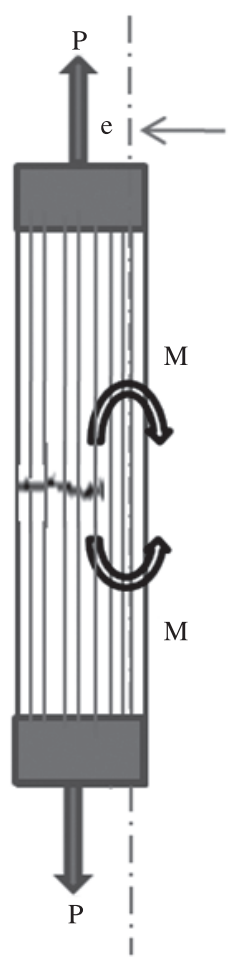

Figure 13. Schematic of state of stress during final fracture region in a composite specimen that failed under tensile load.

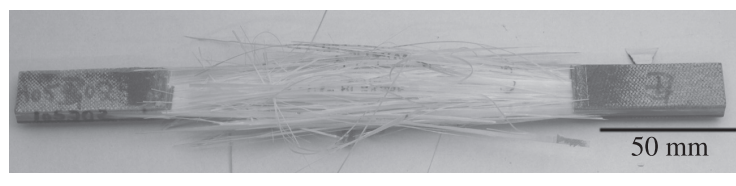

Figure 14. Photograph of GFRP samples that failed under tension. 


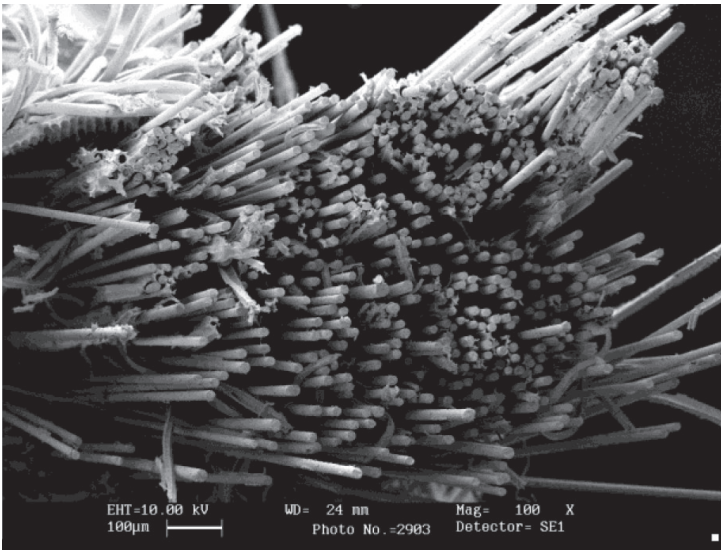

(a)

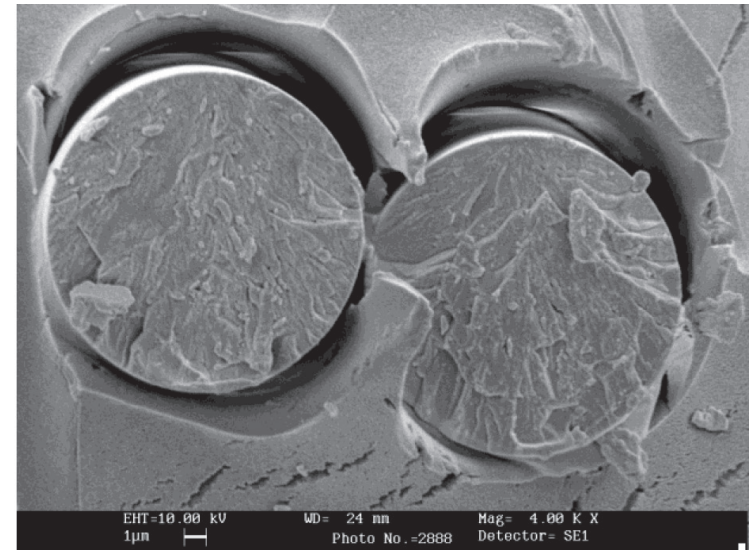

(b)

Figure 15. Fractographic features showing (a) longitudinal splitting, and (b) fibre radials (GFRP specimen).

\section{Conclusions}

Based on the present experimental study, the following conclusions can be drawn.

- Fracture morphology in UD CFRP varies as the crack progresses under tensile load;

- Crack Propagation region in UD CFRP exhibited macrofractographic features like brittle fracture with chevron lines emanating from the crack origin. On the other hand, the final fracture region showed longitudinal matrix splitting;

- Microscopic radial marks were observed in majority of locations on the fracture surface. However, chop marks were noticed only at a few locations in the final fracture region;

- The change in fracture mode in the final fracture region is attributed to the superimposition of bending load that was generated due to eccentricity; and

\section{References}

1. Rakow JF. Failure Analysis of Composite Structures in Aircraft Accidents. In: ISASI Annual Air Safety Seminar Cancun; 2006; Mexico. ISASI; 2006. p. 11-4.

2. Greenhalgh ES. Failure analysis and fractography of polymer composites. Cambridge: Woodhead Publishing; 2008.

3. ASM International Handbook. Composites. 12; 2002.

4. Beaumont PWR and Schultz JM. Failure analysis of composite materials: Fractography. USA: Technomic publication; 1990. p. $119-138$

5. Rosen BW. Tensile failure of fibrous composites. American Institute of Aeronautics and astronautics journal. 1964; 2:1985-1991.

6. Zweben C. Tensile failure of fibre composites. American Institute of Aeronautics and astronautics journal. 1968; 6:2325-2331.

7. Fuwa M, Bunsell AR and Harris B. Tensile failure mechanisms in carbon-fibre reinforced plastics. Journal of Materials Science. 1975; 10:2062-2070. http://dx.doi.org/10.1007/ BF00557484

8. Lifshitz JM and Rotem A. Longitudinal tensile failure of unidirectional fibrous composites. Journal of Materials
- UD GFRP composites exhibited macrofractographic features such as extensive longitudinal splitting and microscopic radial marks on the individual fibre broken ends. There was no transverse fracture in this composite.

\section{Acknowledgements}

The authors thank Mr M K Sridhar, Head, Materials Science Division and Director, NAL for granting permission to publish this work. The authors also thank Dr S K Bhaumik, failure analysis group, Materials Science Division, NAL for extending valuable suggestions and immense support for this work. The assistance of Mr. Kailash singh and Mr. Devaiah, Advanced Composites Division, NAL for the experimental work is acknowledged.

Science. 1972; 7(8):861-869. http://dx.doi.org/10.1007/ BF00550433

9. Cook J and Gordon. A mechanism for the control of crack propagation in all-brttle systems. Proceedings of the royal soceity of Long, Series A, Mathematical and Physical Sciences.1965; 282:508-20.

10. Zhou SG and Sun CT. Failure analysis of Composite laminates with Free edge. Journal of composites technology and research. 1990; 12(2):91-7.

11. Purslow D. Some fundamental aspects of composites fractography. Composites. 1981; 12:241-247. http://dx.doi. org/10.1016/0010-4361(81)90012-4

12. Liechti M, Masters JE, Ulaman DE and Lehman LW. SEM/TEM fractography of composite materials. Ohio: AFWAL-TR-82-4085; 1982.

13. Moloney RAC. Fractography and failure Mechanisms of polymers and composites. Newyork: Elsevier Applied Science; 1989.

14. Shikhmanter L, Eldror I and Cina B. Fractography of unidirectional CFRP composites. Journal of Materials Science. 1989; 24:16772. http://dx.doi.org/10.1007/BF00660949 
15. Richards-Frandsen $\mathrm{R}$ and Naerheim Y. Fracture Morphology of Graphite/Epoxy composites. Journal of composite materials.1983; 17(2):105-13. http://dx.doi. org/10.1177/002199838301700202

16. Kline RA and Chang FH. Composite failure surface analysis. Journal of composite materials. 1980; 14:315-24 http://dx.doi. org/10.1177/002199838001400404

17. Shikhmanter L, Cina B and Eldror I. Fractography of multidirectional CFRP composites tested statically. Composites.1991; 22(6):437-444 http://dx.doi. org/10.1016/0010-4361(91)90201-Q

18. Gilchrist MD and Svensson N. A fractographic analysis of delamination within muldirectional carbon/Epoxy laminates. Composites Science and Technology. 1995; 55(2):195-207. http://dx.doi.org/10.1016/0266-3538(95)00099-2

19. Bascom WD, Boll DJ, Fuller B and Phillips PJ. Fractography of the interlaminar fracture of carbon-fibre epoxy composites. Journal of Materials Science. 1985; 20(9):3184-3190. http:// dx.doi.org/10.1007/BF00545184

20. Gilchrist MD, Kinloch AJ and Mathews FL. Mechanical performance of carbon-fibre and glass-fibre reinforced epoxy I-Beams: II. Fractographic failure observations. Composite
Science and Technology. 1996; 56:1031-1045. http://dx.doi. org/10.1016/0266-3538(96)00068-1

21. Sinclair JH and Chamis CC. Mechanical Behaviour and Fracture Characteristics of Off-axis fibre composites, I - Experimental Investigation. NASA; 1977. NASA Technical Paper.

22. Clements LL. Fractography of unidirectional graphite-epoxy as a function of moisture, temperature and specimen quality. Journal of Materials Science.1986; 21:1853-1862. http://dx.doi. org/10.1007/BF00547919

23. Lee CS, Hwang W, Park HC and Han KS. Failure of carbon/ epoxy composite tubes under combined axial and torsional loading 2. Fracture morphology and failure mechanism. Composites Science and Technology. 1999; 59(12):1789-1804. http://dx.doi.org/10.1016/S0266-3538(99)00041-X

24. Morris GE. Determining fracture directions and fracture Origins on failed graphite/epoxy surfaces. In: Reifsnider KL, editor. Damage in Composite Materials. ASTM; 1979. p. 274-297. ASTM STP 775.

25. Khoshbakht M, Chowdhury SJ, Seif MA and Khashaba UA. Failure of woven composites under combined tension-bending loading. Composite Structures. 2009; 90:279-286. http://dx.doi. org/10.1016/j.compstruct.2009.02.012 